\title{
EXPERIMENTAL AND NUMERICAL STUDY OF DEFECTS IN PRESSURESED CYLINDRICAL SHELLS INSTRUMENTED BY ACOUSTIC EMISSION AND STRAIN GAUGES
}

\author{
A. Elhakimi ${ }^{1}$, A. Daya ${ }^{2}$, A. Laksimi ${ }^{3}$, S. Hariri $^{4}$, Z. Azari $^{5}$ \\ ${ }^{\text {I}}$ Département de Génie Mécanique, Faculté des Sciences et Techniques de Fès, Université Sidi Mohamed Ben \\ Abdellah, BP 2202, Route Imouzzer, Fès, Maroc. \\ ${ }^{2}$ Laboratoire de Modélisation en Mécanique-Energétique et Systèmes Automatiques (LMMESA), Département de \\ Physique Faculté des Sciences et Techniques Errachidia, Université My Ismaïl, BP 509 Boutalamine, 52000 \\ Errachidia, Maroc. \\ ${ }^{3}$ Laboratoire Roberval unité Mixte 6066 CNRS, UTC, BP 20529, 60205 Compiègne, France. \\ ${ }^{4}$ Département Technologie des Polymères et Composites and Ingénierie Mécanique, Ecole des Mines de Douai 941, \\ rue Charles Bourseul, B.P. 10838, 59508 Douai Cedex, France. \\ ${ }^{5}$ LaBPS (Laboratoire de mécanique, Biomécanique, Polymères, Structures), Ecole Nationale d'Ingénieurs de Metz, \\ Université Paul Verlaine-Metz, Ile du Saulcy, F-57045 Metz, France.
}

\begin{abstract}
In order to conduct a comprehensive study on the harmfulness of defects in the pressure vessels, and in order to propose simple rules to characterize the harmfulness of existing defects in pressurized installations. An experimental study based on the monitoring of deformations by strain gauges in the vicinity of defects. In parallel, during pressure testing, the evolution of defects is detected and followed by the acoustic emission method. The specific instrumentation has been designed and implemented. Ministructures ( models) have therefore been carried out with positional defects and different orientation. These experimental results validated by a numerical model of finite elements.
\end{abstract}

Keywords: Pressure vessels, Cylindrical shells, Defect harmfulness, Circumferential and longitudinal Crack, Strain gauges, Acoustic emission, Stress Intensity Factor.

\section{INTRODUCTION}

According to a statistical study on incidents occurring between 1962 and 1967 during the hydraulic tests, 10 vessel structures (among 12700 placed in service) have been damaged [1]. 7 of these incidents are due to cracks discovered in a sheet or a welding. The 3 others are catastrophic accidents. The statistical sample is limited to the boilers and apparatuses with pressure having less than thirty years of service, whose proving pressure is higher than 7 bars and thickness at least $10 \mathrm{~mm}$. Over the 100 years of exploitation of this type of apparatus, 132 damages were raised in service. According to [1], among these 132 ruptures, 7 were catastrophic, and $89 \%$ of them (117 cases) are due to cracks.

The American National Board of Pressure Vessels Inspectors [2] has also compiled a whole of data concerning the ruin of the pressurized apparatuses for the period from 1981 to 1984 [3]. In the same way, the Institute for the Safety of the Engines of TÛV (Technischer ÛberwachungsVerein: Organization of monitoring and technical validation), KELLERMANN and SEIPEL [4] analyzed 547 damages of nonnuclear apparatuses.
This research based on the mechanic fracture, associated with numerical method by finite elements, aims to characterize and to understand better the harmfulness of an existing defect in a structure under pressure. Thus, ministructures, with defects of different positions and orientations, were made. Instrumentation by strain gauges around the defects was carried out. A grid by sensors of acoustic emission is carried out to detect any irreversible deformation in the material (plastic deformation, initiation of defect and follow up its development). Acoustic emission is a technique to monitor defect formation and failures in structural materials used in services or laboratories. Moreover, the method has been developed and applied in numerous structural components, such as pipes and pressure vessels.

\section{EXPERIMENTAL METHOD}

\subsection{Plan Geometry of the Models}

The experimental study is carried out on models made up of a cylindrical binding ring closed by two spherotoric bottoms fig.1. 

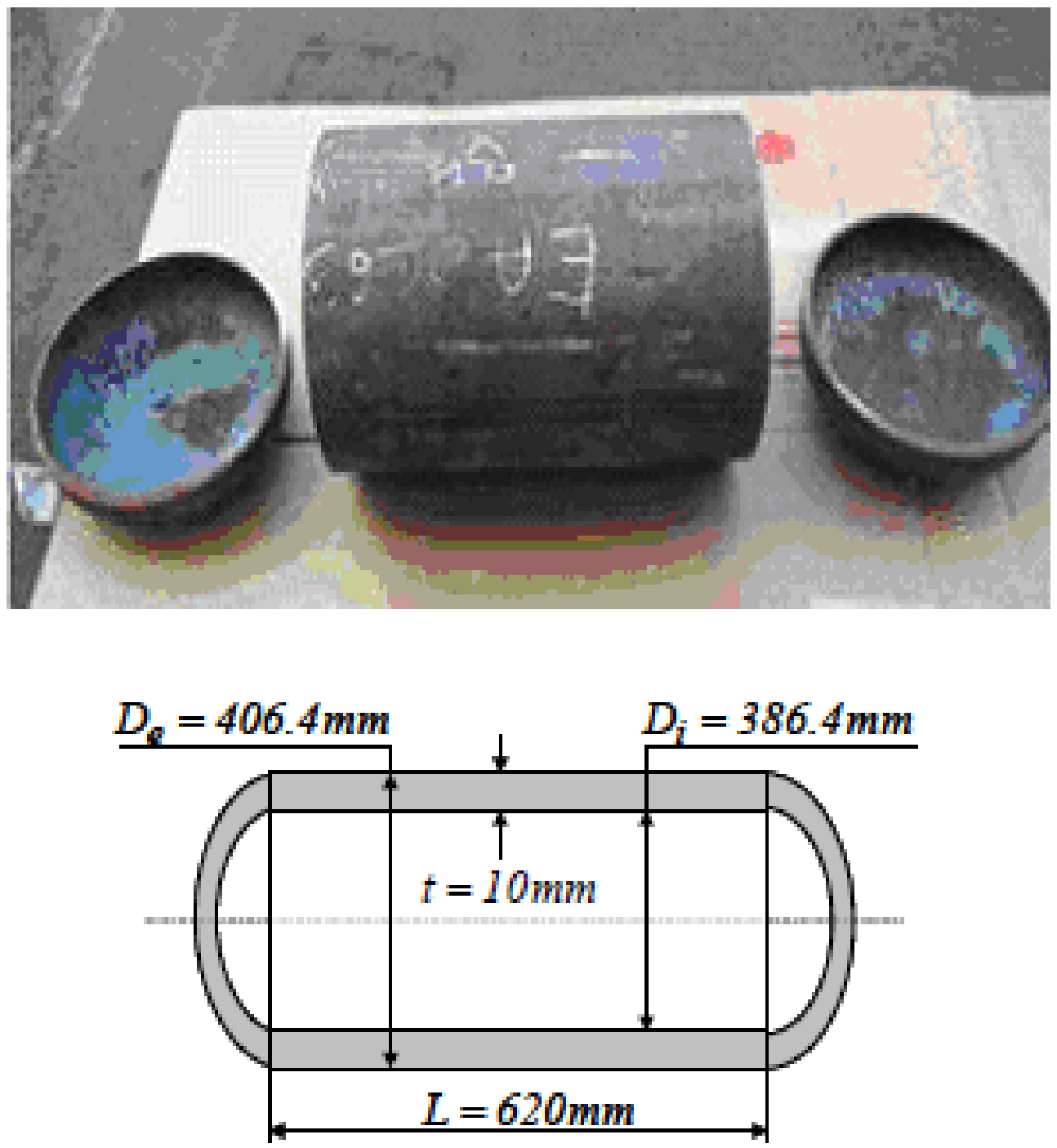

Fig -1: Shape and dimensions of the models

\subsection{Characterization of Material}

In order to determine the mechanical characteristics of used material, we carried out tensile tests at room temperature. The specimens were taken in the longitudinal direction of the cylinder. We machined 6 cylindrical test-tubes according to standard NF A 03-172, fig.2.

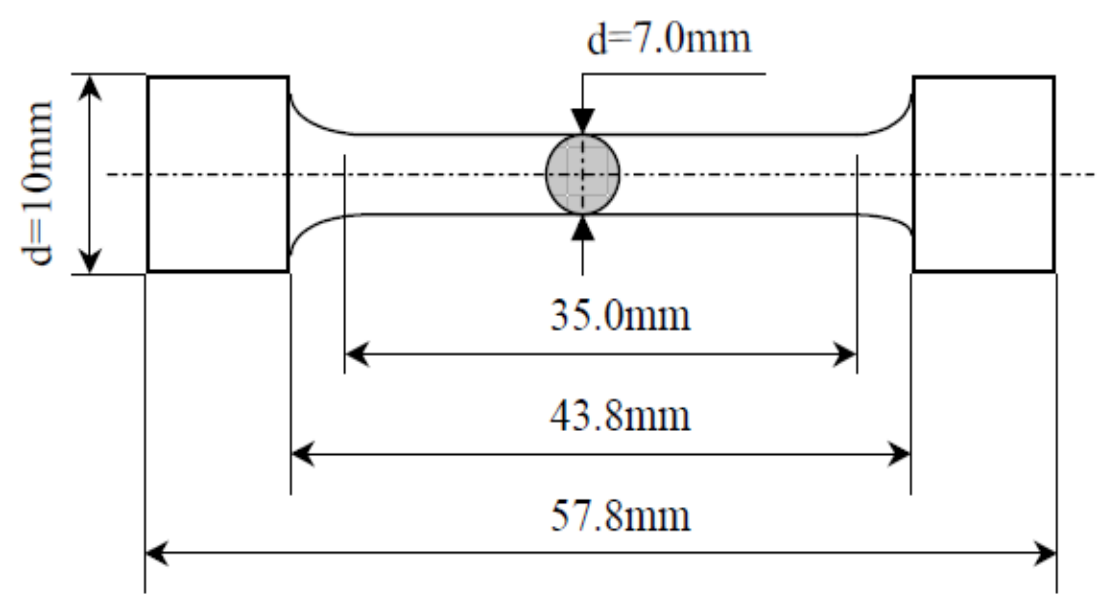

Fig -2: Tensile specimen geometry 
Fig.3 gives the conventional tensile curve showing the ductile behaviour of material. The mechanical and metallurgical characteristics classify this material in the category of P265 GH.

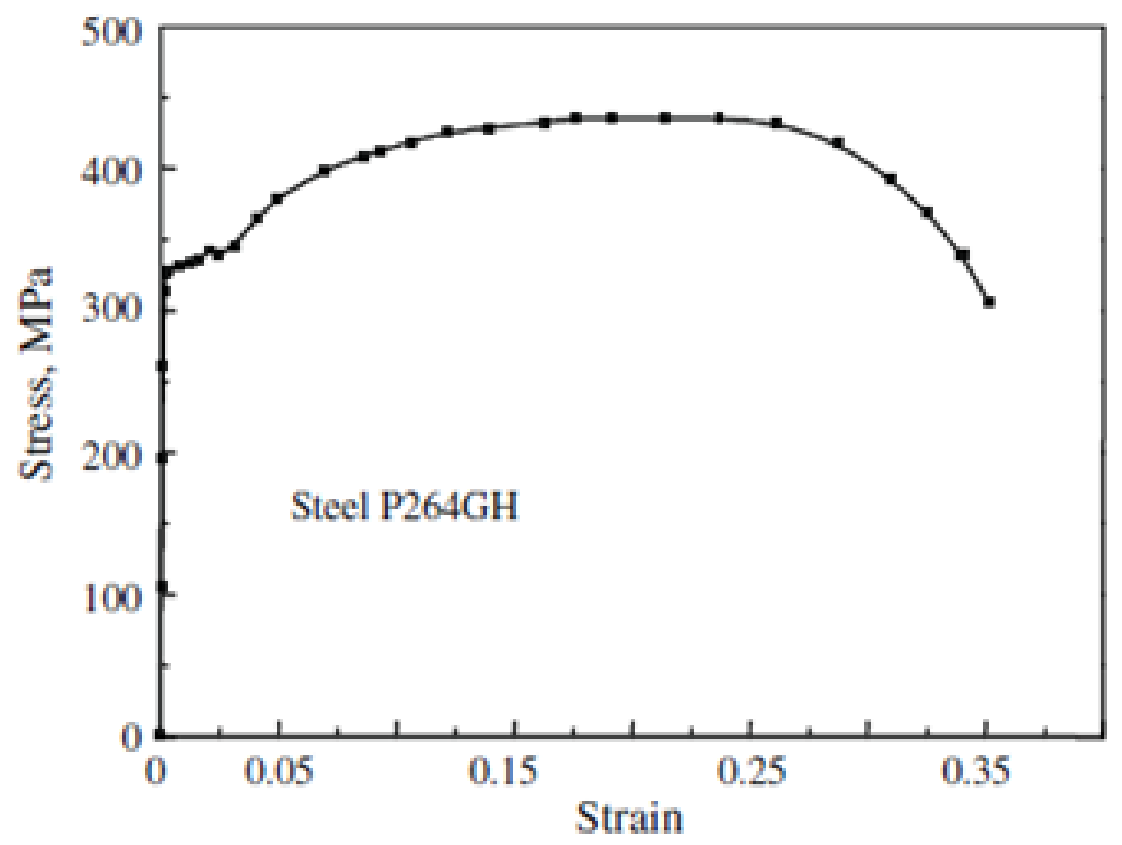

Fig -3: Material behaviour

Table.1 shows the mechanical properties which characterize this material.

Table -1: Mechanical properties of material

\begin{tabular}{|l|l|}
\hline Young modulus & $\mathrm{E}=207000 \mathrm{MPa}$ \\
\hline Poisson's ratio & $v=0.3$ \\
\hline Yield stress & $\mathrm{R}_{\mathrm{e}}=340 \mathrm{MPa}$ \\
\hline Ultimate strength & $\mathrm{R}_{\mathrm{m}}=440 \mathrm{MPa}$ \\
\hline Elongation $\%$ & $\mathrm{~A}=35 \%$ \\
\hline
\end{tabular}

\subsection{Checking of the Pressure Test}

The dimensions of the cylindrical binding ring observe the general terms for the application of the CODAP 2005 [15]. The tests are carried out in laboratory with water fluid. For calculation the service pressure, the nominal stress is taken as $\sigma=147 M P a$. In cylindrical binding ring, the pressure can be calculated using the following equation (obtained from the CODAP):

$$
P=\frac{2 \cdot \sigma \cdot t \cdot z}{D_{m}}
$$

$\mathrm{D}_{\mathrm{m}}:$ average diameter of the envelope,

$\boldsymbol{\sigma}:$ Nominal stress,

$\mathrm{Z}$ : welding coefficient,

As the ring is taken in a tube without welding, $\mathrm{z}=1$ will be taken.

The numerical application of the equation (1) and the previous data, give a pressure $\mathrm{P}=74$ bars.

\subsection{Manufacturing of the Defects}

Semi-elliptic defects on a surface were carried out by electro erosion in order to study their harmfulness in this type of structure. In this article, the external defects are studied (axial and circumferential). They are characterized by two dimensions: the defect depth measured radially (a) and its length (2c), Fig.4. 


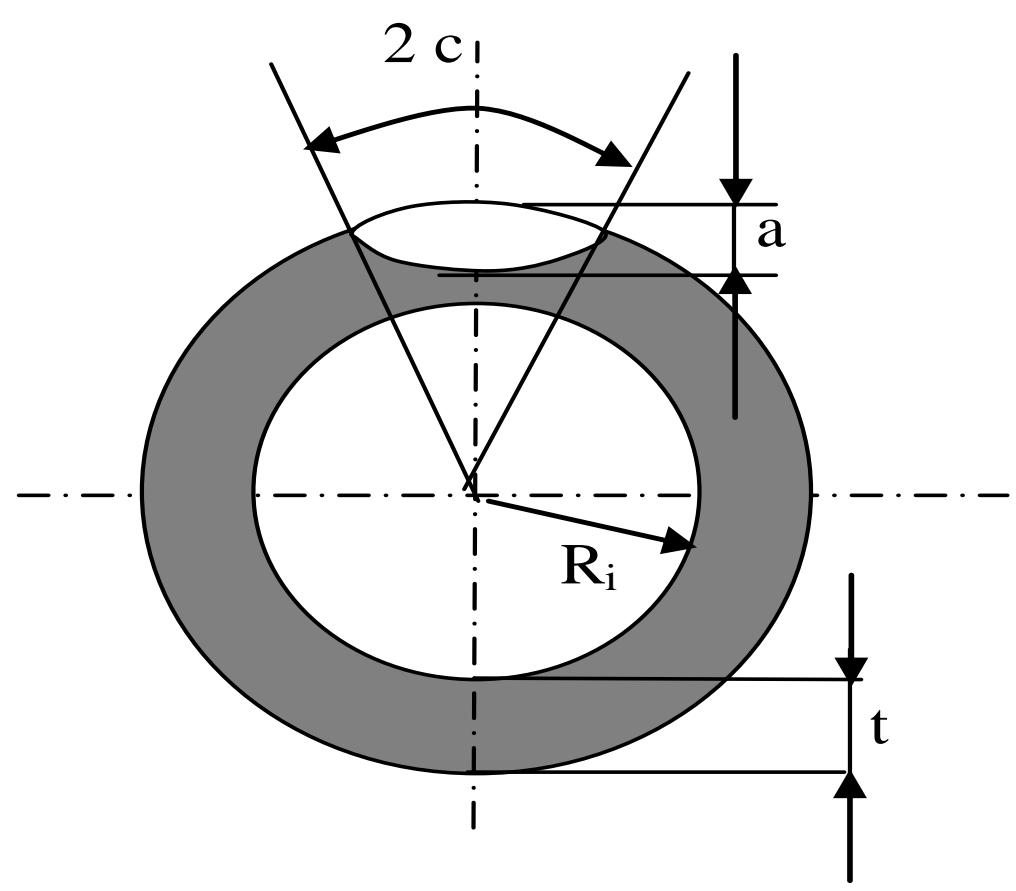

Fig -4a: Circumferential defect.

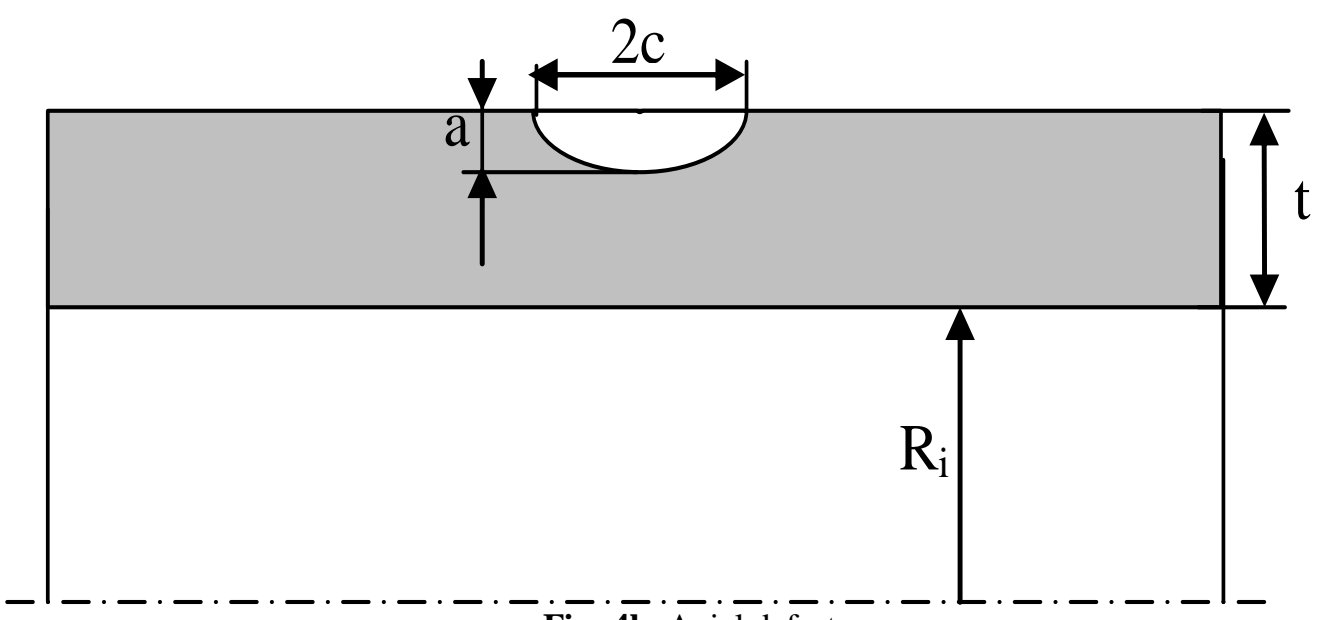

Fig -4b: Axial defect.

The various geometrical parameters and the studied defects are given in the table.2:

Table -2: Geometrical Parameters defects

\begin{tabular}{|c|c|c|}
\hline Structure & Defect orientation & Dimensions \\
\hline \multirow{2}{*}{$\begin{array}{l}\text { External diameter : } \\
\mathrm{Re}=406,4 \mathrm{~mm} \\
\text { thickness } \mathrm{t}=10 \mathrm{~mm}\end{array}$} & Axial & $\begin{array}{l}\mathrm{a} / \mathrm{c}=1 / 4 \\
\mathrm{a} / \mathrm{t}=0.4\end{array}$ \\
\hline & Circumferential & $\begin{array}{l}a / c=1 / 4 \\
a / t=0.4\end{array}$ \\
\hline
\end{tabular}

\subsection{Procedure of Acoustic Emission}

The structure is instrumented by strain gauges and sensors of acoustic emission in order to detect the defect starting. These sensors are of resonant piezoelectric type, their resonance frequency is of $150 \mathrm{Khz}$. The gain of the preamplifier, ensuring at the same time the amplification and the adaptation of the signal, is regulated generally with an amplification range of $40+/-10 \mathrm{~dB}$ with a filtration system adapted to the answer of the sensor. 


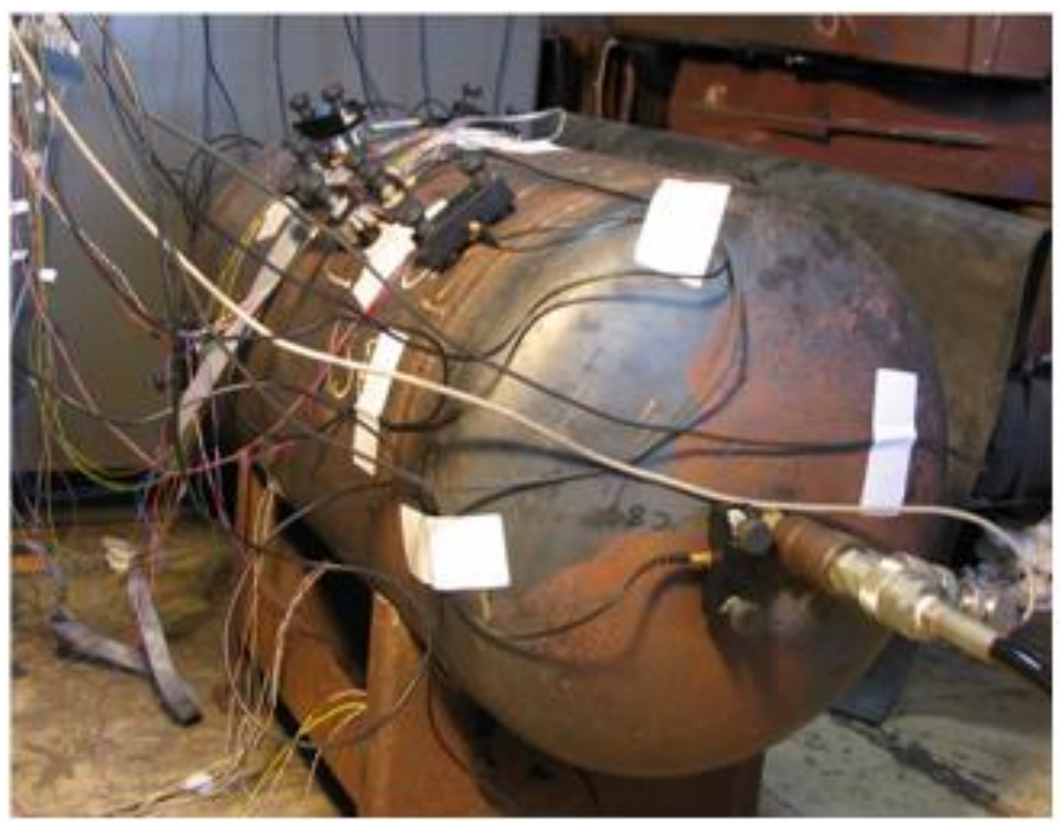

Fig -5: Instrumented model with strain gauges and sensors A.E.

\subsection{Pressurization Cycle}

The cycle of pressurization is carried out in accordance with the recommendations of the Guide to Good Practice for Acoustic Emission Testing of Pressure Equipment [4].

According to this reference, in order to perform the acoustic emission test on the equipment under pressure, the pressure applied must be equal or more than $110 \%$ of the maximum pressure applied (MPA) in service in the last 12 months.

\subsection{Orientation of the Strain Gauges}

The gradients of deformations as a function of the position of the points the most stressed on the models are instrumented by chains of strain gauges allowing measure longitudinal and circumferential deformations. These multidirectional gauges allow showing the total behavior of the pressurized structure. The comparison of the results in terms of deformations allows checking the validity of the numerical results.

Three chains of 5 strain gauges are stuck around the defect. Each one is oriented in long and transverse direction (Fig.6). The chains are noted ( $\mathrm{i}=1$ to 6$)$ and the gauges $J_{\mathrm{k}}(\mathrm{k}=1$ to 5$)$.

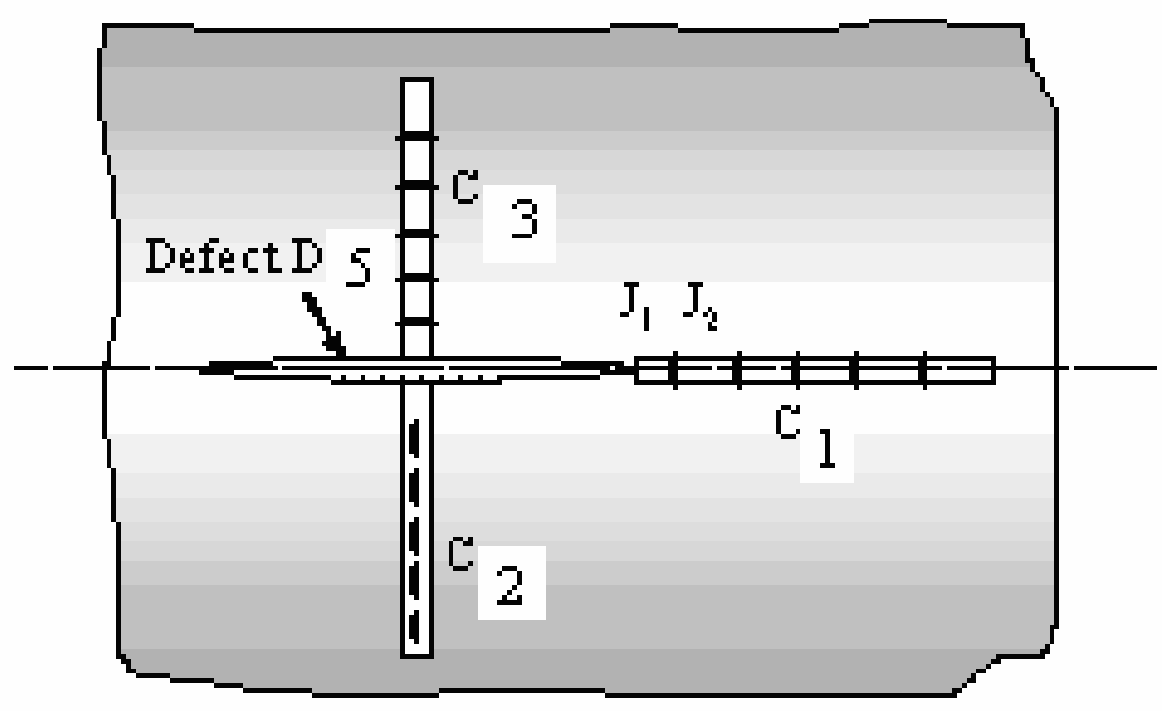

Fig -6a: Position of the chains around axial defects. 


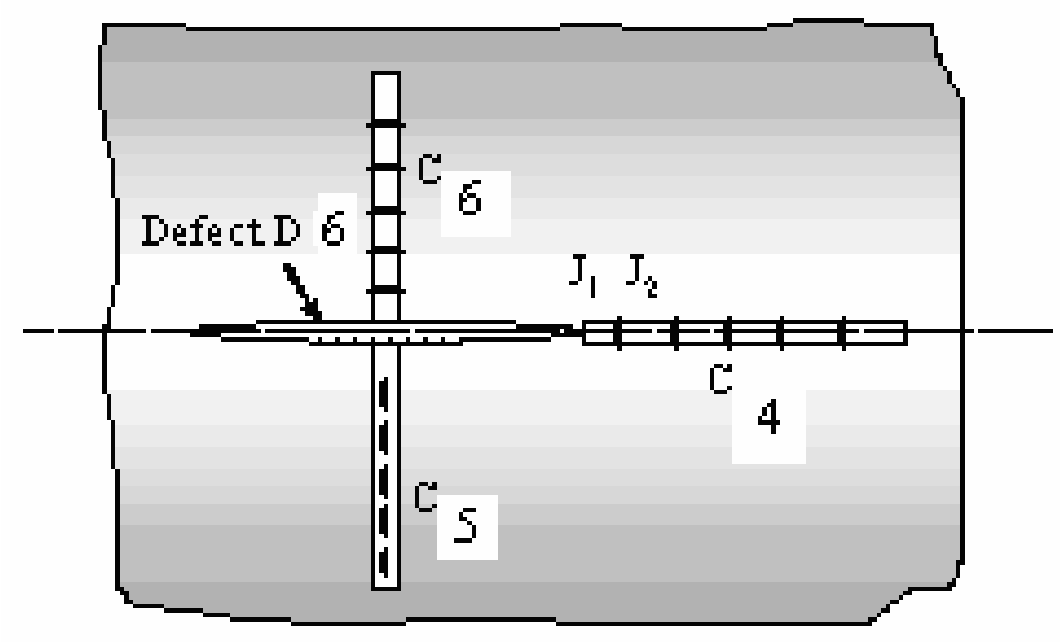

Fig -6b: Position of the chains around circumferential defects.

\section{NUMERICAL STUDY}

\subsection{Mesh Structures}

In order to determine the distribution of strain near the defect in the pressurized cylindrical shell, the finite element method (FEM) was applied. For this purpose, the CASTEM 2000 finite-element software developed by the Centre of Atomic Studies of France has been used. This software allows introducing the current behavior of the material into the finite-element program which makes computations more precise.

For modeling of the cylindrical shell with external defect by FEM, there are some difficulties regarding the calibration and mesh optimization. For example, the calculation procedure requires special elements at the defect front and also at the defect tip "crack blocks", additionally. The internal pressure for all cases was considered $P=25$ bars.

Fig.7 and Fig. 8 show an overview of the model mesh used in this study.

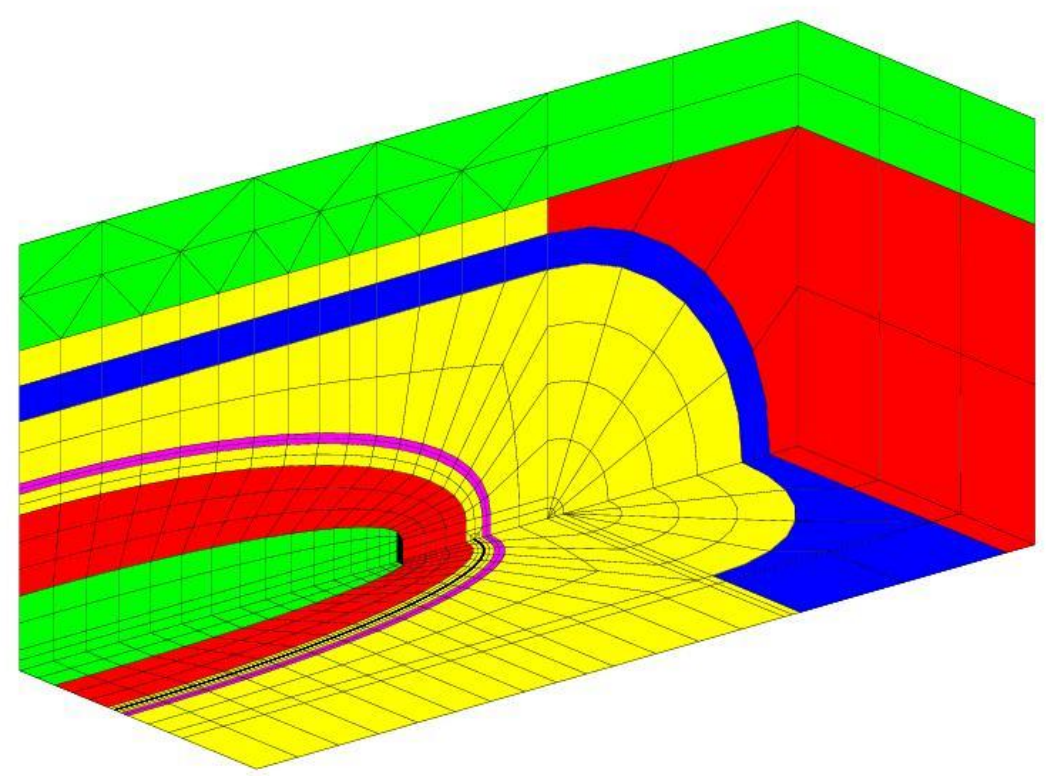

Fig -7a: Crack blocks 


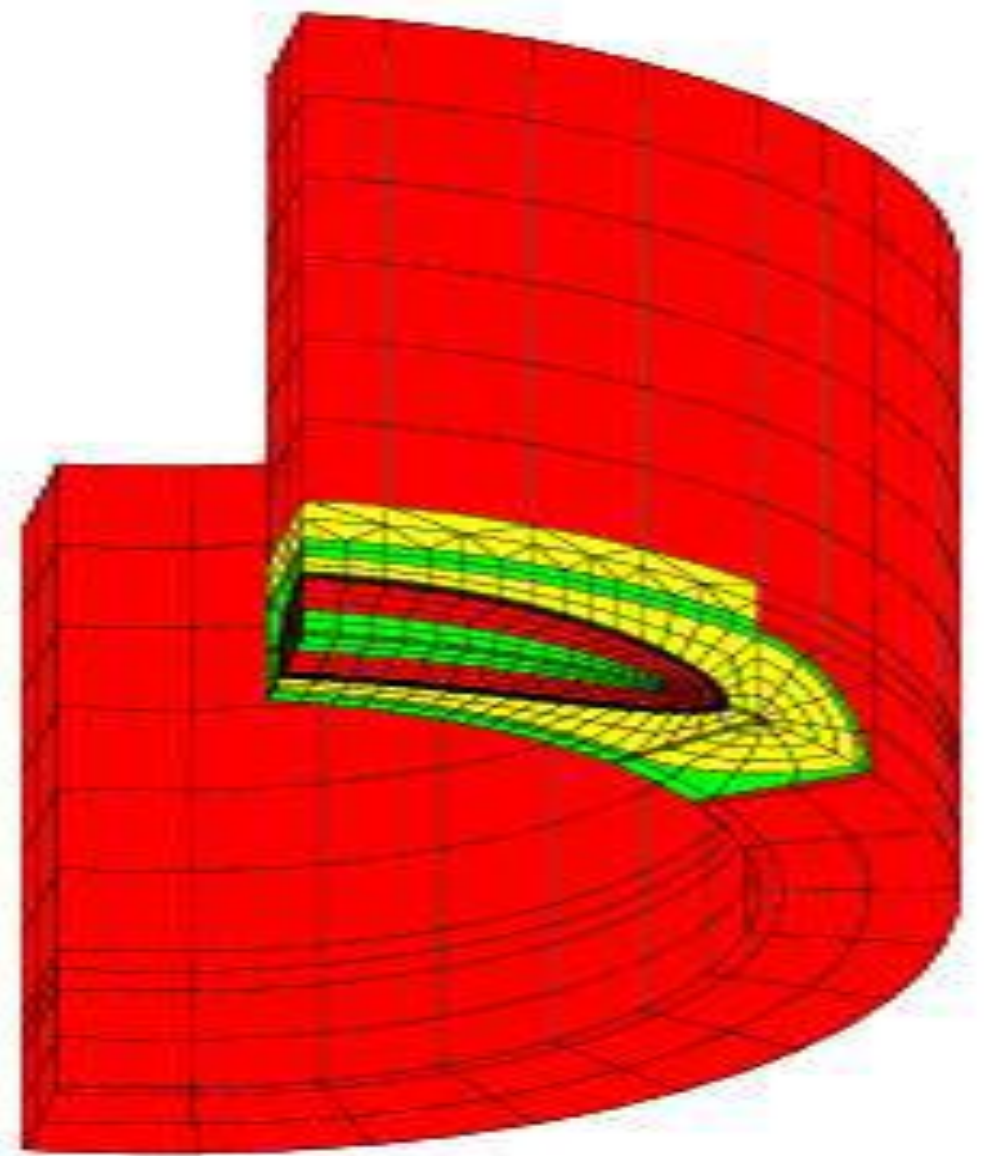

Fig -7b: General view and elements of mesh for cylindrical shell with circumferential semi elliptical crack

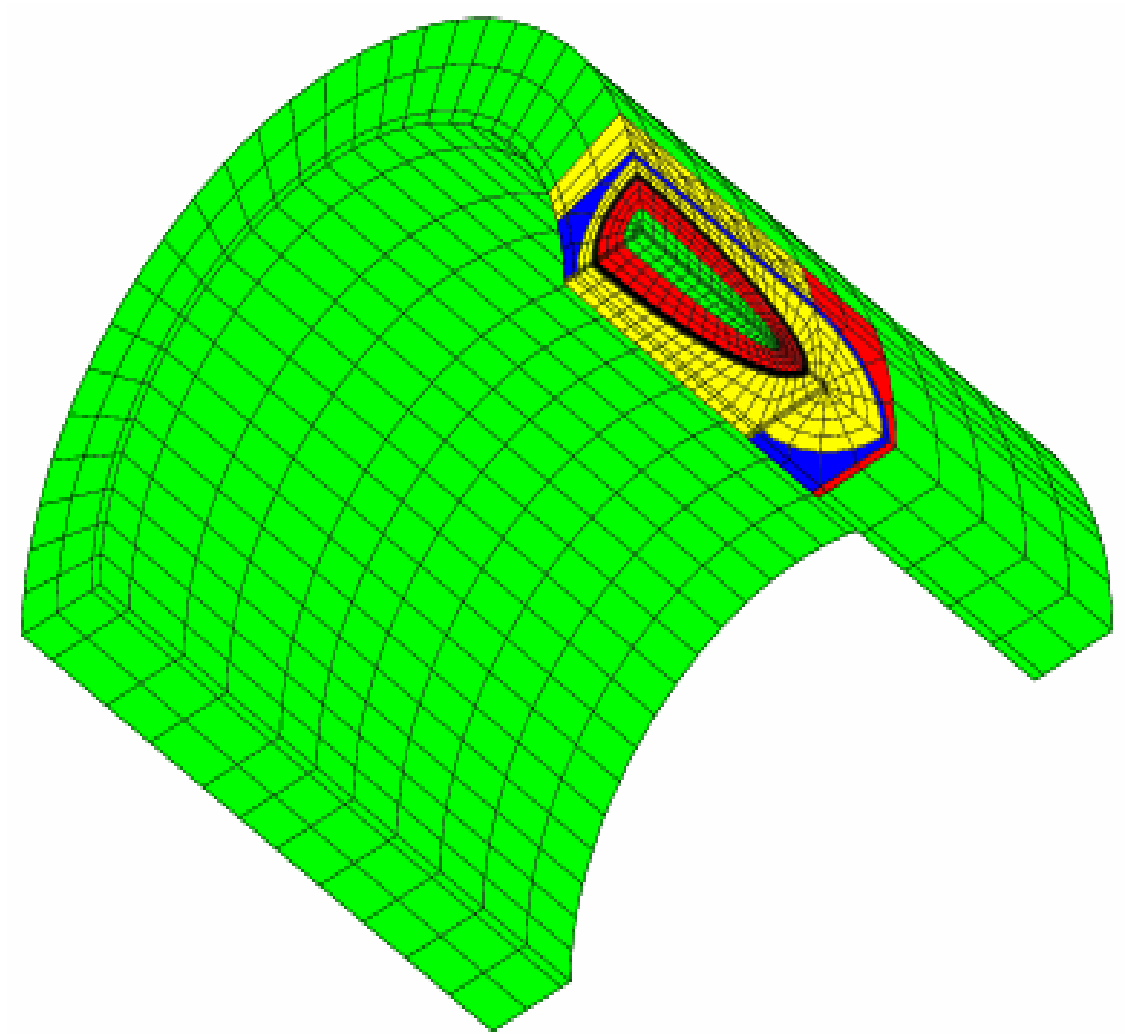

Fig -8: General view and elements of mesh for cylindrical shell with axial semi elliptical crack 


\subsection{Validation of Model}

The superposition principle then allows us to resolve any complicated loading as the sum of simple loads, just developing the local stress field [5-7]. A polynomial expression is generally retained to describe the stress distribution in the vicinity of the crack, knowing that a polynomial of the third degree can represent most of the practical loadings encountered in industrial applications [8-10]. The stress field will thus take the following form:

$$
\sigma\left(\frac{u}{t}\right)=\sigma_{0}+\sigma_{1}\left(\frac{u}{t}\right)+\sigma_{2}\left(\frac{u}{t}\right)^{2}+\sigma_{3}\left(\frac{u}{t}\right)^{3}
$$

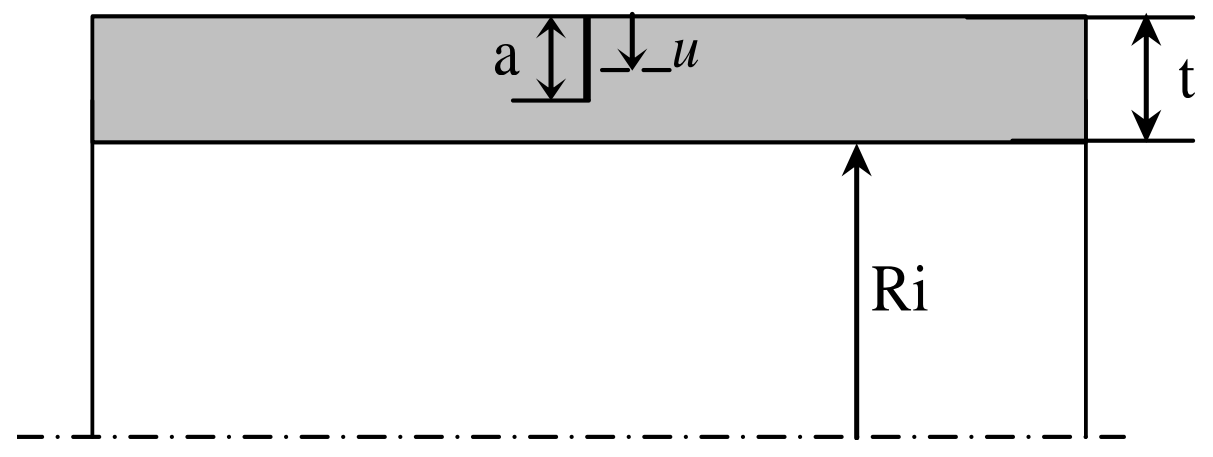

Where $\boldsymbol{u}$ stands for the radial distance between a point inside the inner wall and its projection on the crack emergence surface, independently of the crack shape and size.

The components $\sigma_{0}, \sigma_{1}, \sigma_{2}$ and $\sigma_{3}$ correspond to constant, linear, quadratic and cubic stress distributions, respectively, in the thickness of the cracked structure.

The stress intensity factor is defined from the load components by the following relation [2]:

$$
K_{I}=\left[\sigma_{0} i_{0}+\sigma_{1} i_{1}\left(\frac{a}{t}\right)+\sigma_{2} i_{2}\left(\frac{a}{t}\right)^{2}+\sigma_{3} i_{3}\left(\frac{a}{t}\right)^{3}\right] \sqrt{\pi a}
$$

Before presenting the whole results in the following section, let us validate our numerical model by comparison with other previous numerical solutions. In the case of semi-elliptic cracks, the current point on the front is defined using the parameter $\phi$ as seen in Fig. 9. This angle is equal to $0^{\circ}$ at the surface and $90^{\circ}$ at the bottom. It allows us to study the variation of the stress intensity factor along the crack front.

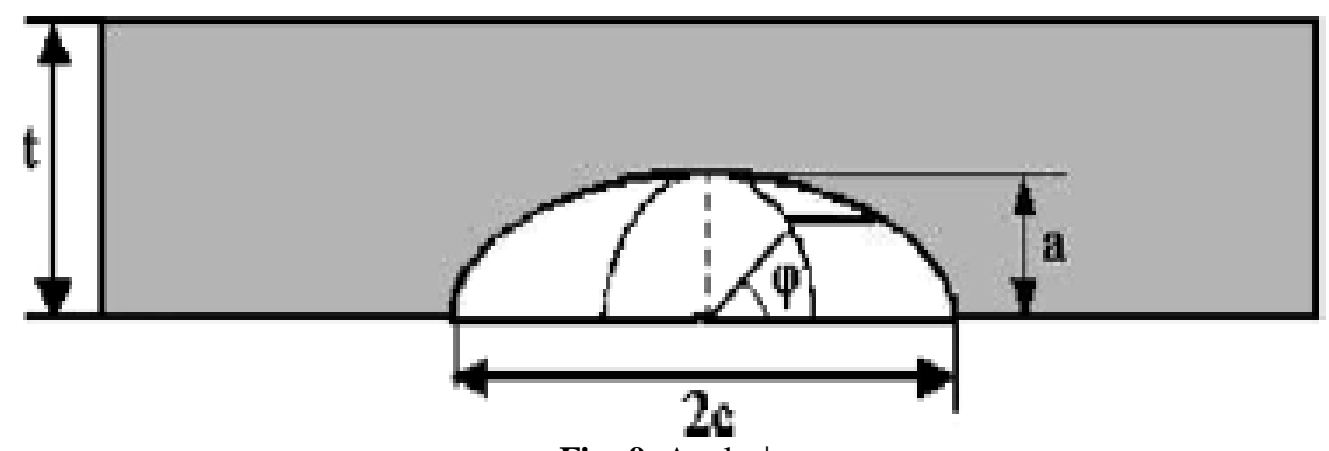

Fig -9: Angle $\phi$

The function of influence $i_{0}, i_{1}, i_{2}$ and $i_{3}$ obtained here for a cylindrical shell is compared to that found by Chapuliot [6]. Fig.10 shows a very good agreement between our numerical results and the previous ones. 


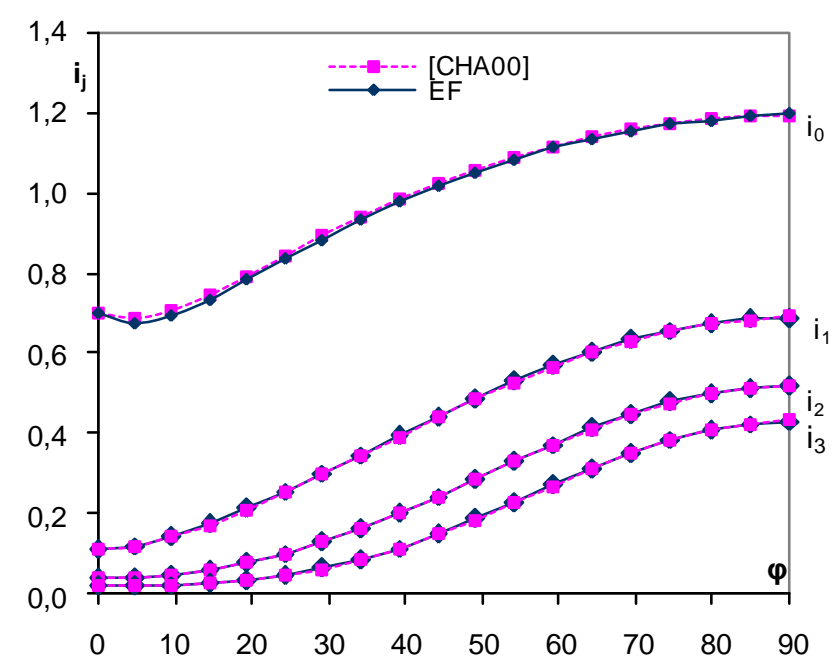

Fig -10: Function of influence in a cylindrical shell with an external semi-elliptic crack $(t / R=1 / 10 ; a / c=1 / 4 ; a / t=0.4)$.

\section{RESULTS AND DISCUSSION:}

\subsection{Gauge Deformations}

The Fig.11 shows the longitudinal deformations measured by the $\mathrm{C} 1$ gauge compared with the numerical results, for an internal pressure of 25 bars.
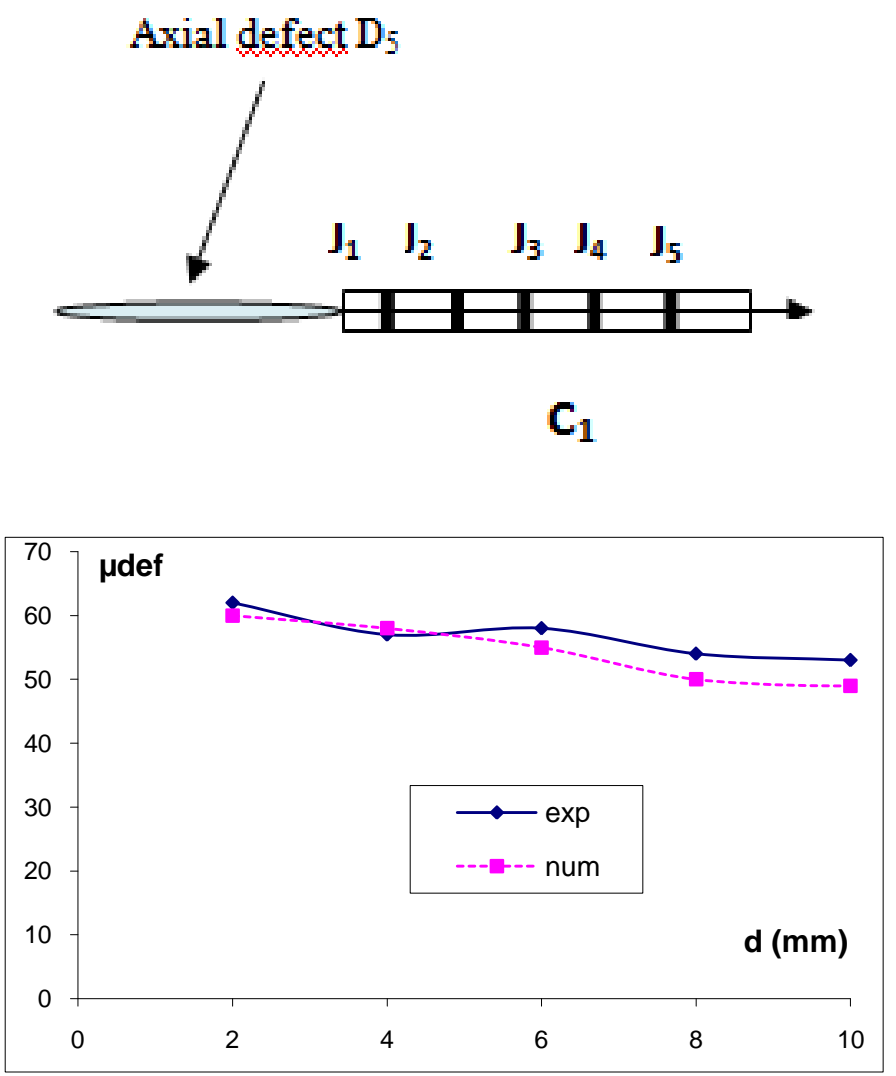

Fig -11: Longitudinal deformation as a function of distance from the defect tip (Chain $\mathrm{C}_{1} ; \mathrm{P}=25$ bars)

A Fig.12, Fig.13 and Fig.14 shows the circumferential deformations measured by C2, and the longitudinal deformation measured by $\mathrm{C} 3$ compared with the numerical results, for an internal pressure of 25 bars. The first $\mathrm{J} 1$ gauge is pasted at $2 \mathrm{~mm}$ from the notch tip; the other gauges ( $\mathrm{J} 2$ to $\mathrm{J} 5$ ) are pasted every $2 \mathrm{~mm}$ along the longitudinal direction. 
The stress concentration effect is observed in a zone close to the notch, this concentration declines with moving away from the notch and the deformation reaches its nominal value for the gauges J4 and J5.

The comparison of the numerical and experimental results shows a good agreement.
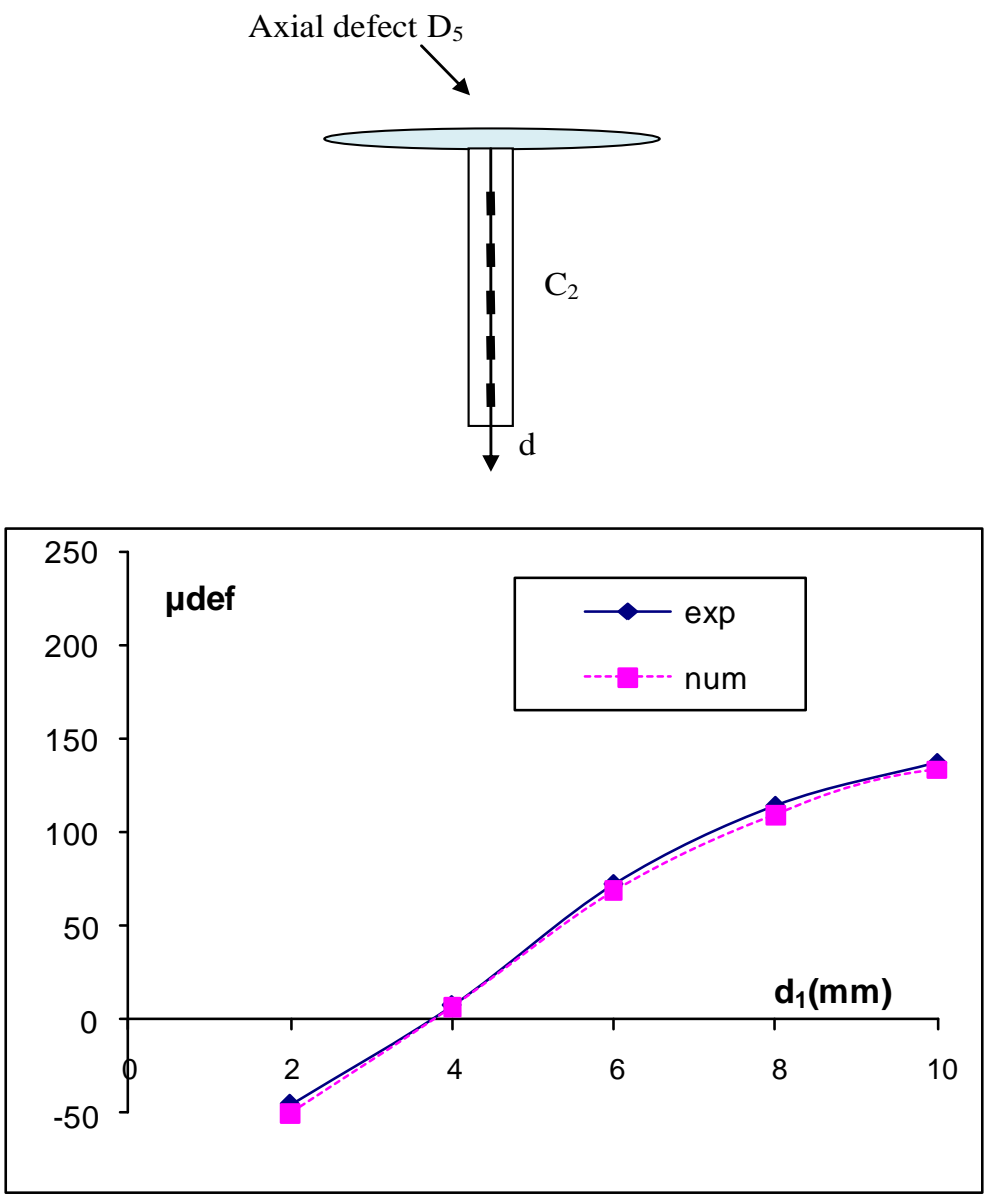

Fig -12: Circumferential deformation as a function of distance from the defect tip (Chain $\mathrm{C}_{2} ; \mathrm{P}=25$ bars).

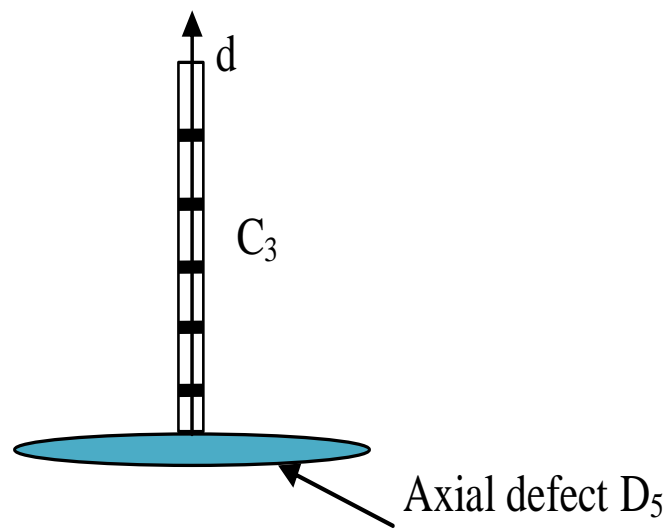




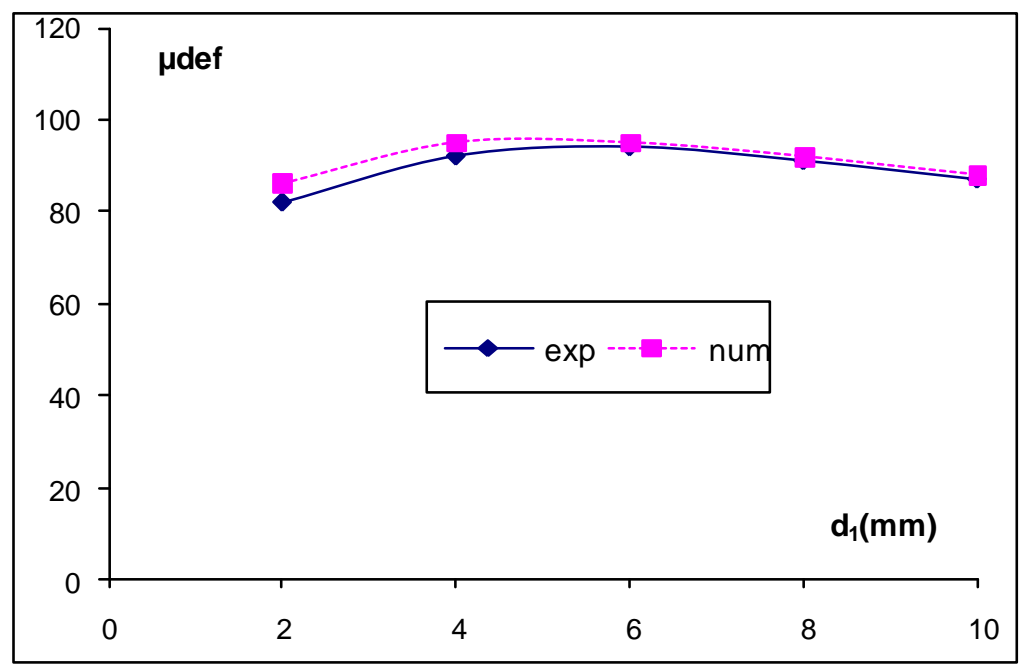

Fig -13: Circumferential deformation as a function of distance from the defect tip (Chain $\mathrm{C}_{3} ; \mathrm{P}=25$ bars).
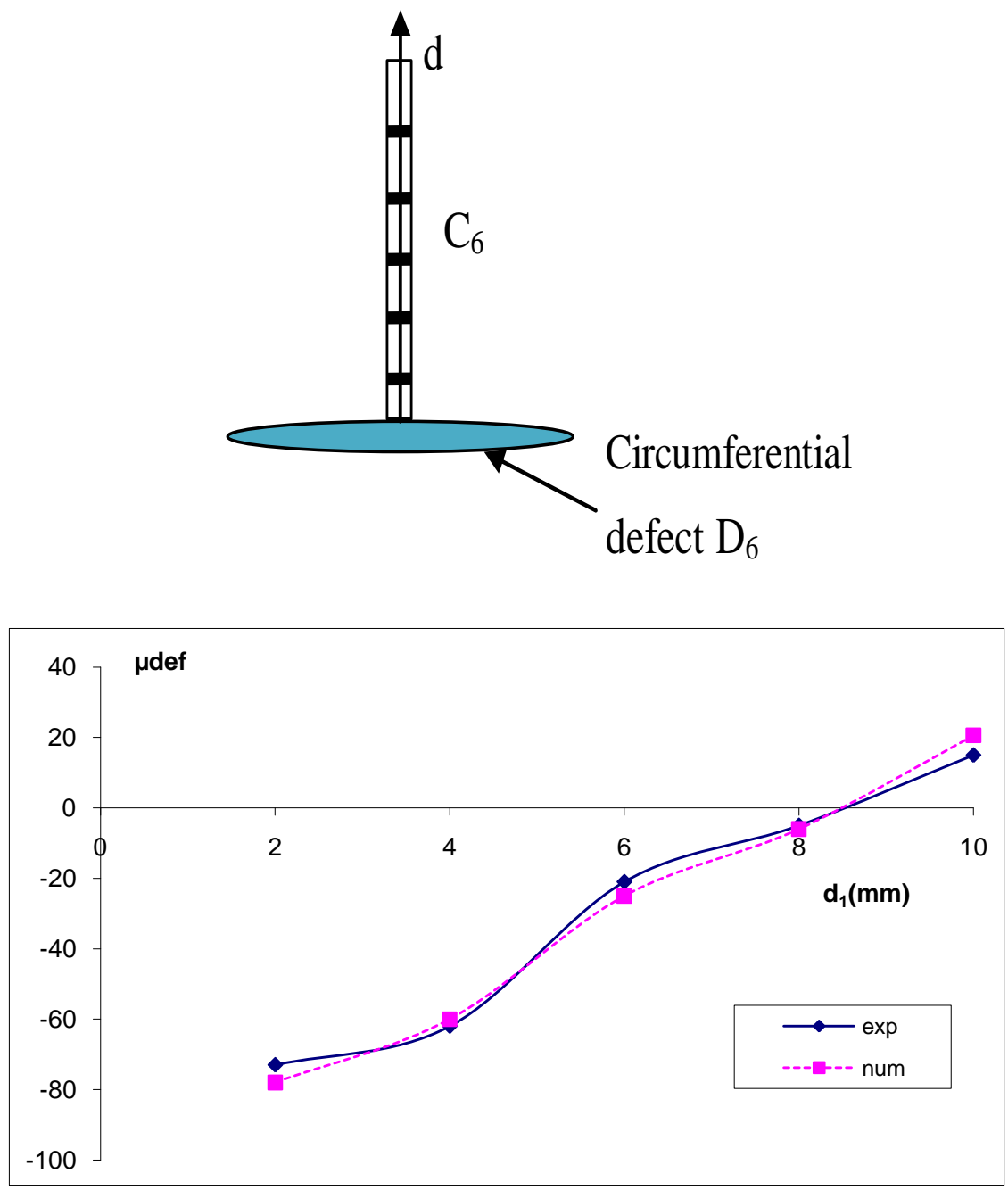

Fig -14: Longitudinal deformation as a function of distance from the defect tip (Chain $\mathrm{C}_{6} ; \mathrm{P}=25$ bars).

In the two configurations of tested models, it should be noted that the experimental results for the curves of deformation distribution around the defects are similar to those obtained by Finite Element method. It is remarkable the quality and the adaptation from our numerical model, particularly in the block-crack, for the axial and circumferential semi-elliptic cracks. 


\subsection{Acoustic Emission Results}

According to standard NF IN 1330-9, Acoustic Emission is a phenomenon of stress wave generation resulting from a local displacement in a material. It is also a phenomenon of sound wave radiation in materials that undergo deformation and fracture processes. This phenomenon appears in the form of release of energy when the material is subjected to a mechanical or thermal stress. Major macroscopic sources of AE in metals are: crack jumps, plastic deformation development, fracturing and de-bonding of hard inclusions includes dislocation movement, slip formation, voids nucleation and growth. The goal of this method in this study is to detect and follow the damage in material in relation with strain gauge and finite elements results.

The cycle of the applied loading is progressive as shown in figure 15. An absence of significant acoustic emission should be noted at the beginning of the test. The acoustic emission appears around 12 bars and evolves gradually according to the rising pressure.

This insignificant acoustic emission activity is due to the noise of water entering into the structure. As the pressure reaches $25 \mathrm{bars}$, the acoustic activity becomes more significant (change of slope of cumulated A.E.) revealing the crack-tip plastic deformation, At this pressure, the gauges closest to the defect indicate the beginning of plasticization of the most stressed zone. A second change in slope of cumulated acoustic activity appears at about 35 bars. This behaviour is in good agreement with the change of the slope observed by the gauges located ahead the defect. Indeed, the deformation recorded by the gauge nearest to the defect ( $\mathrm{d}=2 \mathrm{~mm})$ shows firstly the beginning of plastification at 26 bars (Fig.16). Plasticity increases with the pressure and reaches a significant size for the gauge located at $4 \mathrm{~mm}$ ahead the defect. The corresponding pressure is approximately 34 bars. The absence of acoustic emission during the steady pressure indicates the absence of growth of any defect in material. These observations are in good agreement with previous works [11-12].

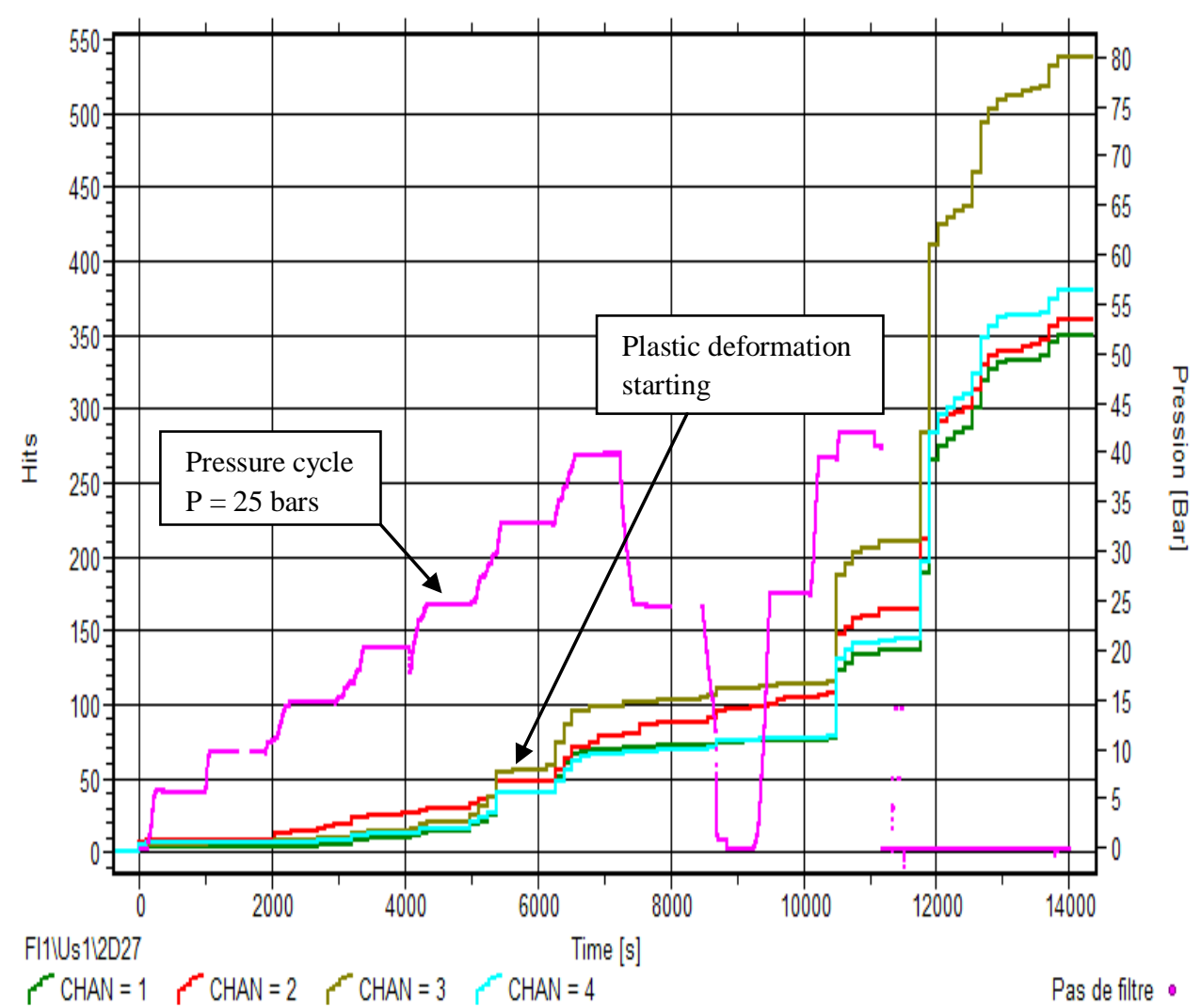

Fig -15: Evolution of Hits as a function of time according to the cycle of pressure.

Hits: cumulated number of acoustic events. 


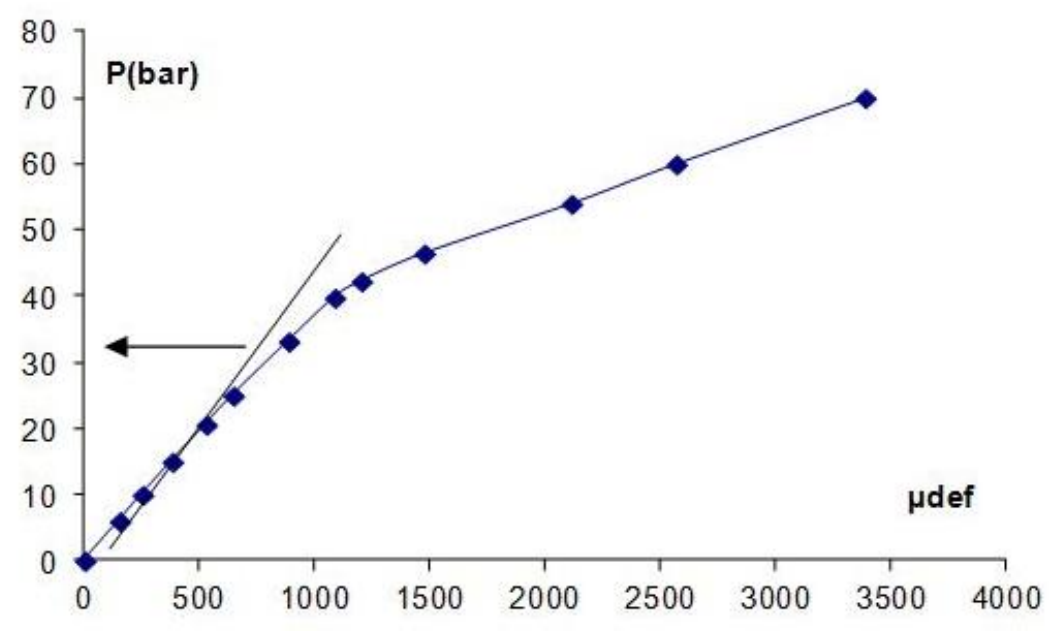

Fig -16: Evolution of the pressure versus deformations measured at a distance $2 \mathrm{~mm}$ from the head of defect.

The experiments [11-12], applied on test-tubes containing welding defects (inclusions, porosities, cracks), show that the difference between the parameters in acoustic emission, under the resumption of the loading (Kaiser effect), can be used in the hydraulic tests of the spherical tanks to determine the presence and the nature of the defects. In fact, under the resumption of the loading, these authors recorded differences between the acoustic signals which depend on the type of defect.

To check the Kaiser effect which specifies that it should not be significant acoustic emission as long as the maximum load previously reached is not exceeded, a discharge of the structure was carried out starting from 40 bars, Fig.17. The acoustic activity begins again only with the pressure level previously reached. Regarding this behavior, the Kaiser effect is well confirmed pointing out the absence of increasing in defects at this pressure level.

The defects initiation propagation would have produced an appearance of acoustic events localised immediately surrounding the defect. Hence, acoustic activity is generated primarily by the plasticity of material.

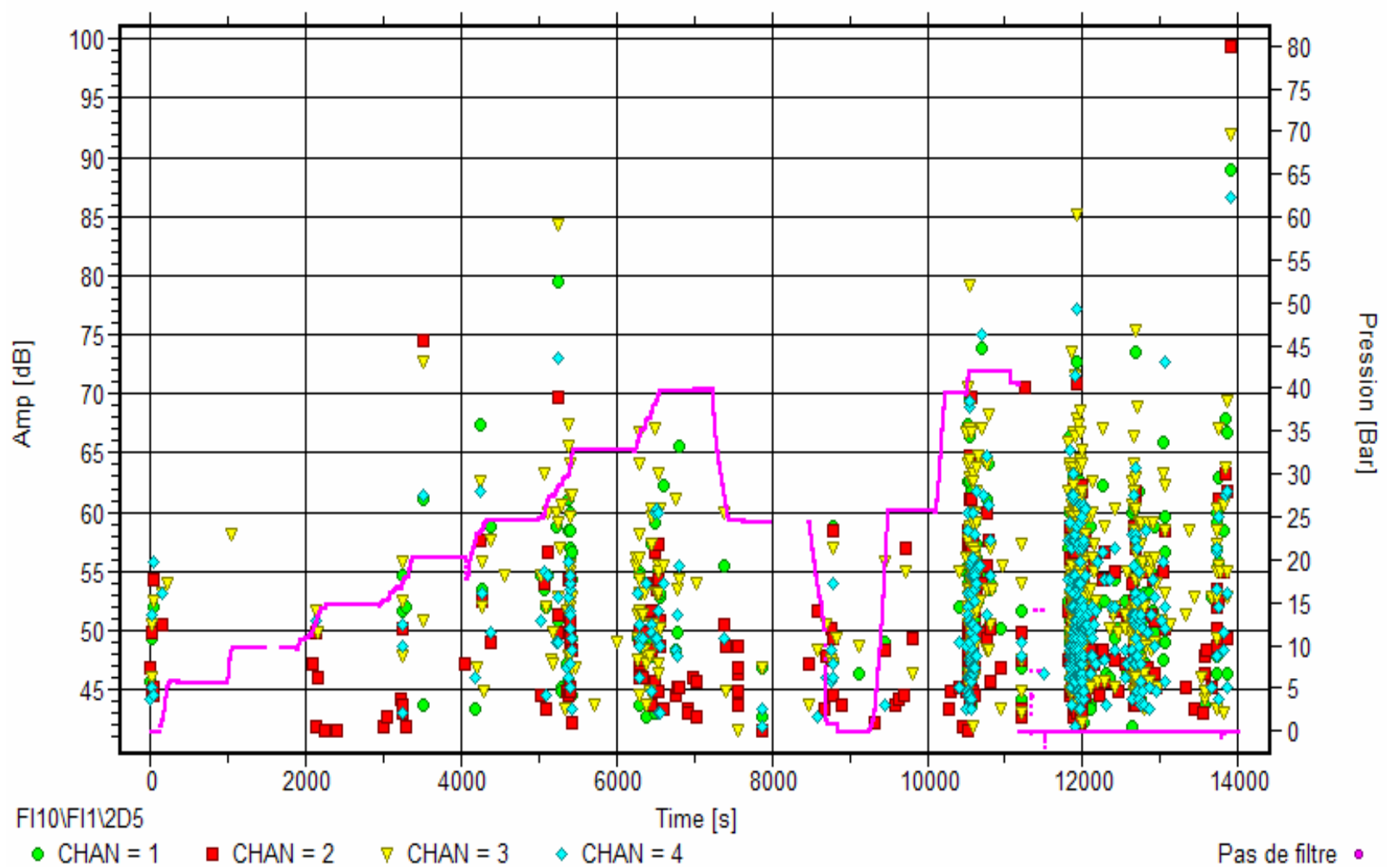

Fig -17: Evolution AE signal as a function of time according to the cycle of pressure. 
The signals of AE recorded are due to a progressive plastification of the structure. This acoustic activity appears primarily during the increase of pressure and disappears while keeping constant pressure. Correlation between the results of measurement of the deformations and those resulting from numerical calculation make it possible to confirm these observations.

The structure was discharged and released throughout 20 hours. The resumption of the increase in pressure shows that the acoustic activity reappears only with a pressure level previously reached, i.e. 70 bars. This confirms the Kaiser effect, which means the absence of evolutionary defects.

After the pressure level of 90 bars, a very high acoustic activity is observed; figure 18, which could be generated by starting of the defect propagation. It is very interesting to note the presence of an acoustic activity after the pressure level of 115 bars which confirms initiation and evolution of the defect. This observation is valid also for the last pressure level of 120 bars.

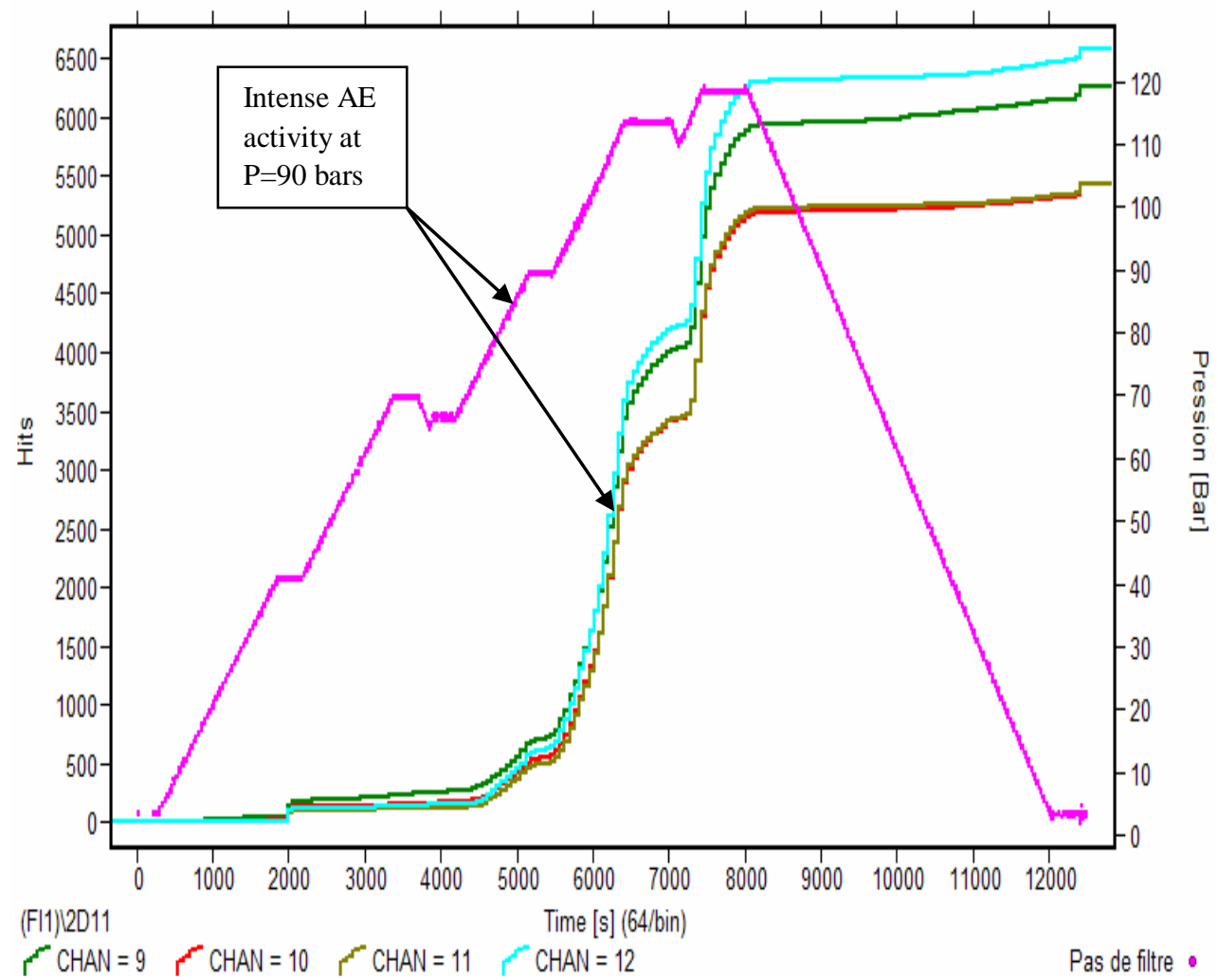

Fig -18: Hits evolution as a function of time according to the cycle of pressure.

\section{CONCLUSION}

Experimental tests were carried out on tubular structures, under a water pressure. Measurements by strain gauges at the head of defects show evolutions in good accordance with the local deformations of defects and decrease while moving away from there.

A numerical method, introducing "crack blocks", allows pointing out local deformations around the defects.

The experimental and theoretical results are in good agreement.

The importance of acoustic emission is to detect the beginning and the evolution of plasticization and defect initiation. The results obtained are in accordance with measurements of the deformations by the strain gauges. This would be major information for numerical approach in order to understand what is happening in the structure.
The most advantage of the acoustic emission is to reveal during a test under pressure and in real time the defects which are propagated and which are likely to lead to a premature rupture of the structure during the laboratory test or in service.

\section{REFERENCES}

[1]. C.A.G Philps., R.G Warwick., A Survey on Defects in Pressure Vessels built to High Standards of Construction, UKAEA Unclassified Report AHSB(B)R162, voir HM Stationery office, London, 1968.

[2]. National Board of Pressure Vessel Inspectors, technical report USA, 1996.

[3]. O. Kellerman., Present View on Recurving Inspection of Reactor Pressure Vessels in the federal Republic of Germany, Agence Internationale de l'Energie atomique, rapports techniques sèrie $n^{\circ} 4$, Vienne, 1981. 
[4]. Practices Guide for Acoustic emission testing of the pressure vessels (A.F.I.A.P.), edition, 2001.

[5] J.J. McGowan., M. Raymond., Stress intensity factor for in.rnal longitudinal semi-elliptical surface flaws in a cylinder under arbitrary loadings, American Society for Testing and Materials pp. 365-380, 1979.

[6]. S. Chapuliot., Formulaire de $\mathrm{K}_{\mathrm{I}}$ pour les tubes avec un défaut de surface semi-elliptique longitudinal ou circonférentiel interne ou externe, Rapport CEA-R-5900.

[7]. R. Brighenti., Surface cracks in shells under different hoop stress distributions, International Journal of Pressure and Piping 77 pp. 503-509, 2000.

[8]. R. Brighenti., Axially-cracked pipes under pulsating internal pressure, International Journal of Fatigue $22 \mathrm{pp}$. 559-567, 2000.

[9]. P.F. Joseph., F. Erdogan., A surface crack in shells under mixed-mode loading conditions, Journal of Applied Mechanics 55 pp. 795-804, 1988.

[10]. P.F. Joseph., F. Erdogan., Surface cracks in toroidal shells, Nuclear Engineering and Design 158 pp. 263-276, 1995.

[11]. C. Ennaceur., A. Laksimi., C. Hervé., M. Cherfaoui., Acoustic emission technique and potential difference method for detecting the different stages of crack propagation in carbon and stainless steel. Journal of Acoustic Emission (JAE), 2005, Vol 22,pp 70-78.

[12]. C. Ennaceur., A. Laksimi., C. Hervé., M. Cherfaoui., Monitoring crack growth in pressure vessel steels by the acoustic emission technique and the potential difference. International Journal of Pressure Vessels and Piping; IPVP 2619-54, pp. 1-8, 2006.

[13]. A. N'Diaye., S. Hariri., G. Pluvinage., Z. Azari., Stress concentration factor analysis for notched welded tubular Tjoints, International Journal of Fatigue, Volume 29, Issue 8, August 2007, Pages 1554-1570.

[14]. A. N'Diaye., S. Hariri., G. Pluvinage., Z. Azari., Stress concentration factor analysis for welded, notched tubular Tjoints under combined axial, bending and dynamic loading International Journal of Fatigue, Volume 31, Issue 2, February 2009, Pages 367-374.

[15]. Code Français de Construction des Appareils à Pression non soumis à l'action de la flamme, édition 2002.

[16]. A. EL Hakimi., P. LE Grognec., S. Hariri., Numerical and analytical study of severity of cracks in cylindrical and spherical shells. Engineering Fracture Mechanics, accepted 29 April 2007.

[17]. A. EL Hakimi., P. LE Grognec., S. Hariri., Z. Azari., A. Laksimi., Etude numérique par éléments finis de la nocivité de défauts dans les coques sphériques, Revue Européenne de Mécanique Numérique, Vol. 16, n²1, pp. 79101, 2007, 15 Septembre 2006.

[18]. A. EL Hakimi., Etude numérique et expérimentale de la nocivité des défauts dans des coques cylindriques et sphériques sous pression soutenu en juin 2006.

[19]. J. Heliot., R.C. Labbens., A. Pelissier-Tanon., Semielliptical cracks in a cylinder subjected to stress gradient, American Society for Testing and Materials pp. 341-364, 1979.

[20]. A. Saffih., S. Hariri., Numerical study of elliptical cracks in cylinders with a thickness transition, International
Journal of Pressure Vessels and Piping, Vol 83, Nº1, pp 35 41, 2006.

[21]. H. Moustabchir., Z. Azari., S. Hariri., I Dmiytrakh., Experimental and numerical study of stress-strain state of pressurised cylindrical shells with external defects, Engineering Failure Analysis 17, 506-5014, 2010. 